\title{
The effects on induced passive rehearsal and the von Restorff phenomenon on the free recall of normals and retardates
}

\author{
JOHN J. WINTERS, JR. \\ E. R. Johnstone Training and Research Center, Bordentown, New Jersey 08505 \\ and \\ THOMAS B. WARD \\ Rider College, Trenton, New Jersey 08602
}

\begin{abstract}
Noninstitutionalized retardates and normal children of equal mental age (approximately 8 years) listened to 11 orders of 20 nouns with no instructions to overtly or covertly rehearse. All subjects were in each of three list conditions: (a) when all words were at the same decibel (dB) level, (b) when the 11 th item was at a higher $\mathrm{dB}$ level, and (c) when the items were repeated at the same dB level using the rehearsal protocol of Rundus (1971). The normals' overall recall was superior to that of the retardates' recall. Repetition of items had no effect on the performance of either group except in the recency portion of the learning curve and on the initial trial for both groups and the fifth trial for the retarded group. The normal group was more susceptible to the von Restorff effect than was the retarded group. These results were discussed in terms of the changing and different recall strategies of the two groups.
\end{abstract}

There were three purposes of this study. One was to determine whether presenting aural stimuli to retarded and normal children in a sequence that is representative of college subjects' rehearsal protocol in a free-recall task would facilitate the children's recall. Another purpose was to determine whether incremented rehearsal of an item within a list would elicit better recall of that item as a result of uniqueness through repetition. A third purpose was to replicate a previous study (Winters \& Attlee, 1974) in which retardates and normals of equal mental age (MA) elicited the von Restorff phenomenon when an incremented decibel (dB) level was the isolating factor, and then to compare recall of items isolated on the bases of incremented $\mathrm{dB}$ level (as in the previous study) with items isolated by incremented repetition (introduced in the present study).

When the mentally retarded have shown a free-recall deficiency relative to their normal MA counterparts, this deficiency has been attributed to, among other hypotheses, the retardates' inadequate organization of information during input (Spitz, 1966), their inconsistent strategy of recall at output (Winters \& Attlee, 1974; Winters, Gerjuoy, Crown, \& Gorrell, 1967), their inefficient use of verbal mediators (Milgram, 1968) and verbal mnemonics (Jensen, 1965), and a deficit in their rehearsal strategy (Ellis, 1970).

The authors are grateful to Ms. Radian, Mr. Attlee, Mr. Reilly, Mr. Elms, and Ms. Rosenhauer of the Jackson Township school system and Mr. Kaltovich of the Florence Township school system, and their respective staffs, for their cooperation. We are also indebted to Ms. Winters for recording the stimuli, Mr. Hoats for his technical assistance, and to Herman H. Spitz for his critical reading of the manuscript. Thomas B. Ward is now at the University of Wisconsin.
Evidence as to whether or not retarded individuals spontaneously rehearse is contradictory, some experiments indicating that they do not [Belmont \& Butterfield (1969, 1971); Brown (1974); Butterfield, Wambold, \& Belmont (1973); Ellis (1970)], other experiments indicating that at least some of them do (Bray, 1973; Glidden, 1972; Herriot \& Cox, 1971; Kellas, Ashcraft, \& Johnston, 1973), and that their rehearsal depends, in fact, upon how well the items are learned (Greenfield, Zieger, Fisher, \& Zeaman, 1974). However, as a group they apparently are less inclined than normals to rehearse spontaneously, which may attenuate their free recall. Atkinson and Shiffrin (1968) have hypothesized that items actively rehearsed in short-term memory will enter long-term memory, and that those items rehearsed the most will be recalled best, accounting for the high level of recall in the primacy portion of the learning curve. Consequently, when rehearsal does not occur, this portion of the curve is depressed and overall recall attenuated. A low-primacy/high-recency serial learning curve has been found in the mentally retarded and young normal children (Ellis, 1970; Kingsley \& Hagen, 1969).

In order to facilitate recall in the primary portion of a list, as well as overall recall, retardates have been trained to cumulatively rehearse a list of stimuli actively (Brown, Campione, Bray, \& Wilcox, 1973; Kellas et al., 1973) and to use the pause patterns of normal subjects (Belmont \& Butterfield, 1971). Retardates also have demonstrated long-term retention of a rehearsal strategy (Brown, Campione, \& Murphy, 1974; Kellas et al., 1973). Cumulative rehearsal, i.e., repetition of 
presented, immediately preceding, and previous items in a list, is a requisite for enhancing list learning since it has been demonstrated with college subjects (Fischler, Rundus, \& Atkinson, 1970; Glanzer \& Meinzer, 1966) and retarded subjects (Bray, 1973; Leicht \& Johnson, 1970) that segmented rehearsal, i.e., repetition of an item only when it is presented, deleteriously affects recall in the primacy portion of a list. In this study, a cumulative rehearsal strategy typical of college subjects' protocol (Rundus, 1971) was presented to retardates and normals of equal MA in order to determine whether free recall could be facilitated without training in active and overt rehearsal.

Rundus and Atkinson (1970) proposed a procedure for the direct observation of rehearsal processes in free recall, a procedure which Rundus (1971, Experiment II) later used to obtain rehearsal protocols on the von Restorff phenomenon. His subjects were instructed to repeat items aloud and to remember the words in red (isolated item). Since the isolated items were repeated more often, it would be of interest to determine whether the rehearsal protocol of college subjects would not only increase the overall recall of young normal and retarded individuals, but also elicit the von Restorff effect.

The relatively few studies which have compared retardates with normals on the von Restorff phenomenon have indicated that (a) normals are more susceptible to it than retardates but (b) both groups demonstrate the von Restorff effect in a variety of isolating conditions (e.g., chromatic, auditory, and meaningfulness uniqueness). Winters and Attlee (1974) recently found that when incremented $\mathrm{dB}$ level is the isolating factor, retardates and normals of equal MA demonstrate this phenomenon to the same degree. However, both groups performed at ceiling on the isolated item in a 10 -item list. Lengthening a list should attenuate performance on the isolated item and determine whether the two groups are equally susceptible to this effect when audition ( $\mathrm{dB}$ level) is used.

The importance of the degree of susceptibility with audition as an isolating factor has both theoretical and practical implications. Theoretically, it is of interest to know the relative effects of the auditory von Restorff on retardates and normals, since these two groups differ in the degree of susceptibility to the visual von Restorff. If modality does affect susceptibility, then another facet of retardates' behavior can be identified. In the applied sense, if it can be demonstrated again that presenting verbal material at discriminately higher $\mathrm{dB}$ levels reliably predicts recall of an item, or items, then this technique can be used in settings in which audition is the mode of learning.

\section{METHOD}

\section{Subjects}

Thirty-six children of average intelligence $(\overline{C A}=8.03$ years,
$\mathrm{SD}=.52$ years; $\overline{\mathrm{IQ}}=104.94, \mathrm{SD}=7.52 ; \overline{\mathrm{MA}}=8.40$ years, $\mathrm{SD}=$ .56 years) and 36 noninstitutionalized retarded children $(\overline{C A}=11.92$ years, $S D=3.08$ years, $\overline{\mathrm{Q}}=69.59, \mathrm{SD}=9.20$; $\overline{\mathrm{MA}}=8.10$ years, $\mathrm{SD}=1.43$ years) were tested. The Slosson intelligence test was administered to a larger pool of subjects in both intelligence groups, and subjects were selected from each group on the basis of their comparable mental ages. The retardates were free of gross motor defects. Members of both groups were from the middle- and low-SES levels.

\section{Stimuli and Procedure}

The stimuli consisted of a training list of four nouns and three lists of 20 nouns. There were three experimental list conditions. A master recording was made for each of the three experimental lists. Eleven different orders of each 20-word list were recorded at a $5-\mathrm{sec}$ rate with a $90-\mathrm{sec}$ intertrial interval between orders for free recall. Each of the 11 learning trials was immediately preceded by a "beep" and followed by a "click" to indicate the beginning and the end of a learning trial. In the control condition $(\mathrm{C})$, the lists were transcribed directly from the master tape. In the von Restorff condition (VR), the lists were again transcribed from the master tape but the 11 th word in each trial was transcribed at a higher $\mathrm{dB}$ so that the control items had a $\overline{\mathrm{dB}}$ of $80.26(\mathrm{SD}=1.83)$ and the isolated items had a $\overline{\mathrm{dB}}$ of 99.64 $(\mathrm{SD}=2.10)$.

In the rehearsal condition ( $R$ ), each of the 11 trials was again preceded and succeeded by a "beep" and a "click," and the first presentation of each word was in the same order as in the $C$ and VR conditions, but they were recorded at a $1-\mathrm{sec}$ rate in a cumulative rehearsal sequence.

Following Rundus' (1971, Experiment II) protocol, the order of presenting the words on each trial in the $R$ condition was such that the mean number of sets in which items were recalled was 2.35 for control items and 5.00 for the isolated item; Rundus' values were 2.30 and 4.50 , respectively. The mean number of rehearsals for the control items was 4.25 and for the isolated item 7.00; Rundus' values were 4.17 and 6.50 , respectively. The mean number of different items in each rehearsal set was 2.50 for control items and 3.00 for the isolated item; Rundus' values were 3.10 and 2.90 , respectively. The differences in Rundus' values in this last instance is the smallest of all those reported. In this study, the difference is also the smallest but in the opposite direction. Whatever influence the difference in the mean number of different items in a rehearsal set has on recall is undetermined but, relative to other protocol parameters, it is the most minimal.

Since no protocol for rehearsal of items at the beginning or end of the list was reported by Rundus in his VR experiment, the list was constructed so that the number of repetitions of the first two items was the same as the isolated item (seven), and decreased by one on each two succeeding items until Item 7 when repetitions of the control items remained at four and decreased to three on the last two items. Again, a master recording was made and transcribed onto another tape for the experiment. Trial duration was the same for all three conditions $(100 \mathrm{sec})$.

Four different orders of the training list were recorded at a 5 -sec rate with a 10-sec intertrial interval for free recall. Each subject received four training trials prior to each session to demonstrate that when the signal ("click") was heard at the end of each presentation, he was to recall the list until he heard the other signal ("beep"), at which time he was to listen to the next presentation of the list. The subject's task was to free recall as many words as possible between the "click" and the "beep." No subject had difficulty following instructions.

All subjects were tested in each of the three conditions on three separate days with a different list for each condition. When the $\mathrm{C}$ and VR conditions were administered, the session was preceded by original training, or retraining, with the training list at a 5 -sec interstimulus interval. When the $R$ condition was 
administered, the training list, which was recorded at a 1-sec interstimulus interval with each word repeated contiguously five times, was presented.

\section{RESULTS}

During the training and test conditions, no subject recalled while the list was being presented and all subjects started to free recall after the appropriate signal.

The scores analyzed were the number of items recalled at each serial position in each condition. Preliminary analyses indicated that no reliable sex or order of presentation differences were present and these variables were excluded from further analyses. For the training sessions, a 2 by 3 ANOVA (Groups by Conditions) indicated that recall among the three conditions did not differ, but the normal group did recall more items than the retarded group $(F=20.96$, $\mathrm{df}=1 / 70, \mathrm{p}<.01$ ). The interaction was not significant.

A 2 by 3 by 20 ANOVA (Groups by Conditions by Serial Positions) on the experimental data revealed that the main effects of Groups $(F=9.87, \mathrm{df}=1 / 70$, $\mathrm{p}<.01)$ and serial position $(\mathrm{F}=199.12, \mathrm{df}=19 / 1,330$, $\mathrm{p}<.01$ ) were significant as were the Groups by Serial Position ( $F=5.18, \mathrm{df}=19 / 1,330, \mathrm{p}<.01)$ and the Conditions by Serial Positions $(F=8.24, \mathrm{df}=38 / 2,660$, $\mathrm{p}<.01$ ) interactions.

An examination of Figure 1, which graphically depicts the percent of items recalled correctly by the two groups by order of input (serial position) over the 11 trials, will indicate the main effects of groups, serial position, and their interaction.

The normals recalled more than the retardates, recall varied as a function of order of input (primacy-recency effect) and the von Restorff effect, and there was a relatively greater difference in performance between the two groups in the primacy and medial portions of the curves as compared with the recency portion of the curve.

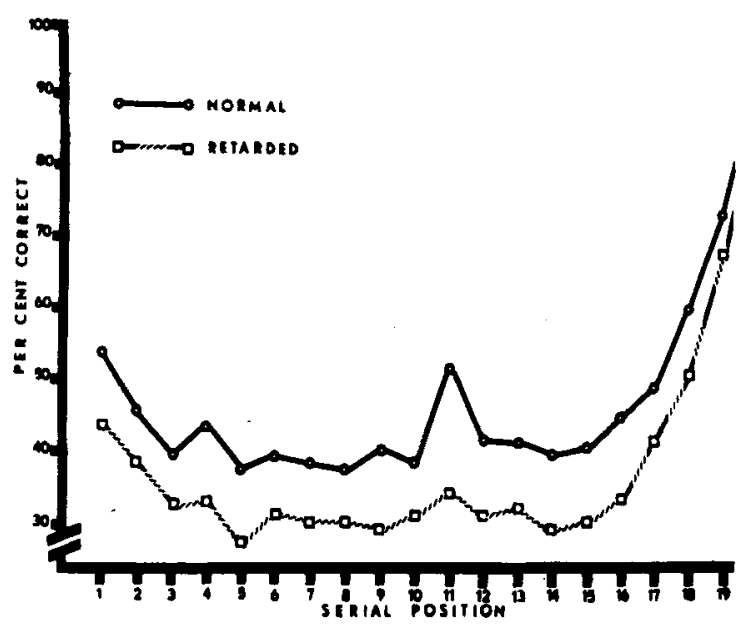

Figure 1. Percent of items recalled correctly by the normal and retarded groups at each serial position.



Figure 2. Percent of items recalled correctly by both groups in the rehearsal (R), control (C), and von Restorff (VR) conditions at each serial position.

The Conditions by Serial Position interaction is demonstrated in Figure 2. Here, differences occurred among the three conditions in the 11 th serial position $(F=20.22, \mathrm{df}=2 / 213, \mathrm{p}<.01)$ with recall in the VR condition higher than recall in either the $C$ or $R$ conditions (Tukey $B, p<.01$ ), which did not differ from each other.

In order to determine relative performance of the two groups in the 11th position of the VR condition and to determine what effect, if any, the $R$ condition had, Figure 3 shows the percent recalled correctly by each group in each condition at each serial position.

It is apparent that any beneficial effects of rehearsal for either group occurred only in the recency portion of the list. The cumulative rehearsal of items, in and of itself, did not enhance primacy performance. Also, items in the 11 th position of the $R$ condition, though repeated almost twice as often as the control items in that position, fared no better than other items in the $R$ condition prior to the effect of recency, and were only slightly superior to the control items in that position.

In separate analyses it was found that, in the VR condition, the normal group recalled the 11 th item significantly more often than items in that position in the $C$ and $R$ conditions $(F=19.40, d f=2 / 105, p<.01$; Tukey B, $\mathrm{p}<.01$ ), with the two latter groups not differing. Similar results were found for the retarded group $(\mathrm{F}=5.32, \mathrm{df}=2 / 105, \mathrm{p}<.01 ;$ Tukey $\mathrm{B}, \mathrm{p}<.01)$, but the two groups on the isolated item did differ. A comparison of recall ratios of the isolated item in the VR condition, i.e., number of isolated items recalled/total recall in the VR condition, revealed that the normals had a higher ratio of recall than did the retardates $(t=2.92, d f=70, p<.01)$, and the overall correlation between ratio of recall and IQ was .27 $(\mathrm{df}=70, \mathrm{p}<.05)$. Although this correlation does not account for much of the variance, it does suggest that 

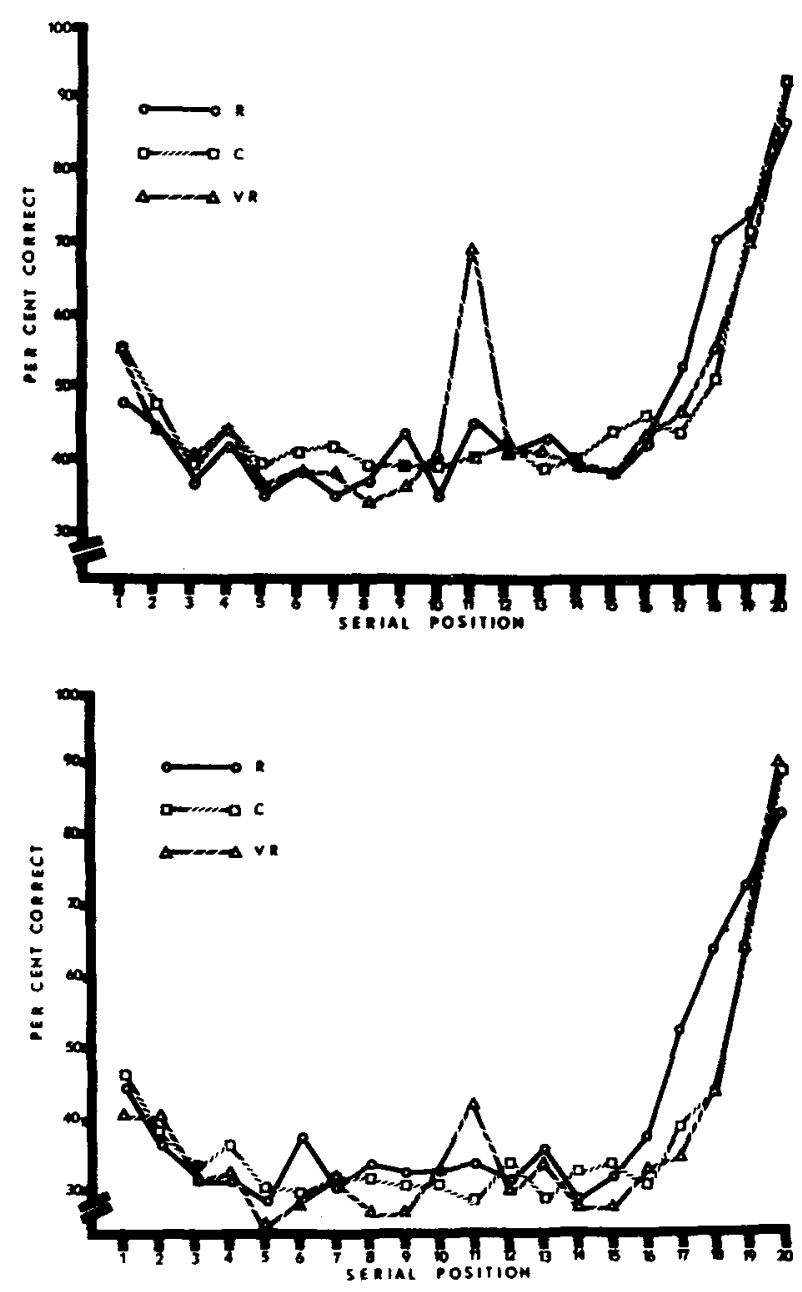

Figure 3. (Above) Percent of items recalled correctly by the normal groups in the rehearsal (R), control (C), and von Restorff (VR) conditions at each serial position. (Below) Percent of items recalled correctly by the retarded group in the rehearsal (R), control (C), and von Restorff (VR) conditions at each serial position.

higher-IQ subjects tended to recall the isolated item with a relatively greater frequency than did lower-IQ subjects. One reason for this may have been in their strategy of recall: the average position in which the isolated item was recalled in a list was lower for the normal group $(\mathrm{t}=3.19, \mathrm{df}=70, \mathrm{p}<.01)$, indicating that the normal group recalled the isolated item earlier than did the retarded group. This suggests that the strategy of the higher-IQ group was to recall the isolated item sooner, which resulted in a relatively higher recall of the isolated items. Battig, Allen, and Jensen (1965) and Brown and Thomspon (1971) reported that newly learned items were recalled earlier than other items. Apparently, their subjects attended to a new item, held it in memory, and recalled the item early to assure successful recall. The superior retention of the isolated item by the normal group reflects their ability to retain the item better, and their earlier recall of the isolated item suggests a strategy similar to that of adult subjects. It is also plausible that the recallability of a unique item would cause it to be recalled earlier. If this were the case, the retardates, who also demonstrated superior recall of the isolated item, should have recalled isolated items earlier. This they did not do.

This study differed from Rundus' (1971) study in one main respect. The protocol obtained by Rundus was derived from 11 separate lists of 20 words each; here the same 20 words were used repeatedly for 11 trials, but in random arrangements. Another comparison would be to evaluate performance of the two groups on the first trial of each condition in order to determine the effects of repetition and the VR phenomenon on newly learned words. A 2 by 3 (Groups by Conditions) ANOVA on performance on the first trial revealed that the normals were superior to the retardates $(F=7.46, d f=1 / 70$, $\mathrm{p}<.01)$ and conditions differed $(\mathrm{F}=11.17, \mathrm{df}=2 / 140$, $p<.01$ ), with the $R$ condition superior to the $C$ condition $(p<.05)$ and the VR condition (Tukey B, $\mathrm{p}<.01)$.

Although the interaction was not significant, which suggests that both groups benefited from the $R$ condition, $t$ tests for related means revealed that for the normal group only the $\mathrm{R}$ and $\mathrm{VR}$ conditions differed reliably from each other $(t=2.03, d f=35, p<.05)$ whereas for the retarded group both the $R$ and $C$ conditions $(t=3.25, \mathrm{df}=35, \mathrm{p}<.01)$ and the $\mathrm{R}$ and $\mathrm{VR}$ conditions differed $(\mathrm{t}=4.26, \mathrm{df}=35, \mathrm{p}<.01)$. The $\mathrm{R}$ condition was superior in each comparison. However, on the first trial, the VR effect was not demonstrated by either group in either the R or VR condition.

In view of the results on the first trial, a 2 by 3 by 11 (Groups by Conditions by Trials) ANOVA was performed to compare performance over trials. Again, the normals were superior to the retardates $(F=9.51$, $\mathrm{df}=1 / 70, \mathrm{p}<.01$ ). The effect of trials was significant $(F=80.88, \mathrm{df}=10 / 700, \mathrm{p}<.01)$ as was the Groups by Trials interaction $(F=3.08, \mathrm{df}=10 / 1,400, p<.0 \mathrm{I})$. There were no significant effects involving conditions. Figure 4 shows the learning curves for each condition by each group.

It will be noticed that, aside from the 1 st and 10 th trials, performance in the $\mathrm{R}$ condition was never superior for the normal group. However, for the retarded group, performance in the $\mathrm{R}$ condition was better than performance in the $C$ and VR conditions on 9 of the 11 trials although, when comparisons were made on each trial, only on the first and fifth trials $(F=8.40$, $\mathrm{df}=2 / 105, \mathrm{p}<.01$ ) was performance in the $\mathrm{R}$ condition significantly better than performance in the other two conditions.

\section{DISCUSSION}

The mere presentation of a representative rehearsal strategy of higher mental age normals was not sufficient to aid the overall recall of mental retardates. Active 
overt rehearsal and/or training is apparently required. However, on a single trial in which new material is presented, passive rehearsal aids the recall of both young normal and retarded persons, with the retarded group benefiting more. Superior recall by both groups on the initial trial indicates that the rehearsal protocol presented was appropriate to facilitate overall recall. If novel stimuli were presented on each succeeding trial (e.g., Rundus, 1971) or if only one trial was given, subjects' reliance on experimenter's protocol should have elicited superior recall in this condition. Decrease in the superiority of the $\mathrm{R}$ condition with repeated stimuli suggests the progressively lesser dependence of recall on rehearsal protocol and the dissipation of the original benefits of rehearsal due to the differential repetition of previously recalled items. Jacoby (1973) has stated that the purpose of rehearsal is to maintain items in memory, but unless the items are processed for long-term memory, rehearsal is no aid to recall. An experimenter-determined protocol may not foster further processing to aid in overall recall when lists are repeated. Active overt rehearsal and/or training is apparently required to facilitate learning by the mentally retarded. Thus, the value of passive rehearsal may be confined to a situation in which novel stimuli are presented or the subject has not yet adopted a recall strategy.

Once a strategy has been adopted, the normal subjects tend to use their own specific strategies and another strategy does not assist recall, whereas the retarded group is more inclined to use the R strategy supplied by experimenter, as indicated in Figure $4 \mathrm{~b}$. It has been reported that young normals do organize lists differently from retardates (Winters \& Attlee, 1974), and that they change organizational strategies during learning (Nelson, 1969).

That recall may not be enhanced by the increased repetition of an item in the middle of a list is suggested by Einstein, Pellegrino, Mondani, and Battig (1974). They found that when their adult subjects were free to overtly rehearse items, the isolated item was recalled better than control items but were not rehearsed more. In a related study, Einstein et al. (1974, Footnote 5), reported that the isolated item was rehearsed less than control items. As suggested by those authors, it is possible that Rundus' (1971) protocol was influenced by instructions to recall the unique item. In this study at no time did highly repeated words aid recall of an item by either group.

The finding that performance in the primacy portion of the list was not enhanced by the $R$ condition is contrary to expectations, since the words in that portion of the list also were presented more frequently than words in later portions of the list, with the exception of the 11 th position. These results indicate that any benefit derived from presentation of a rehearsed list is from the recency portion, which in turn suggests that, in this case,
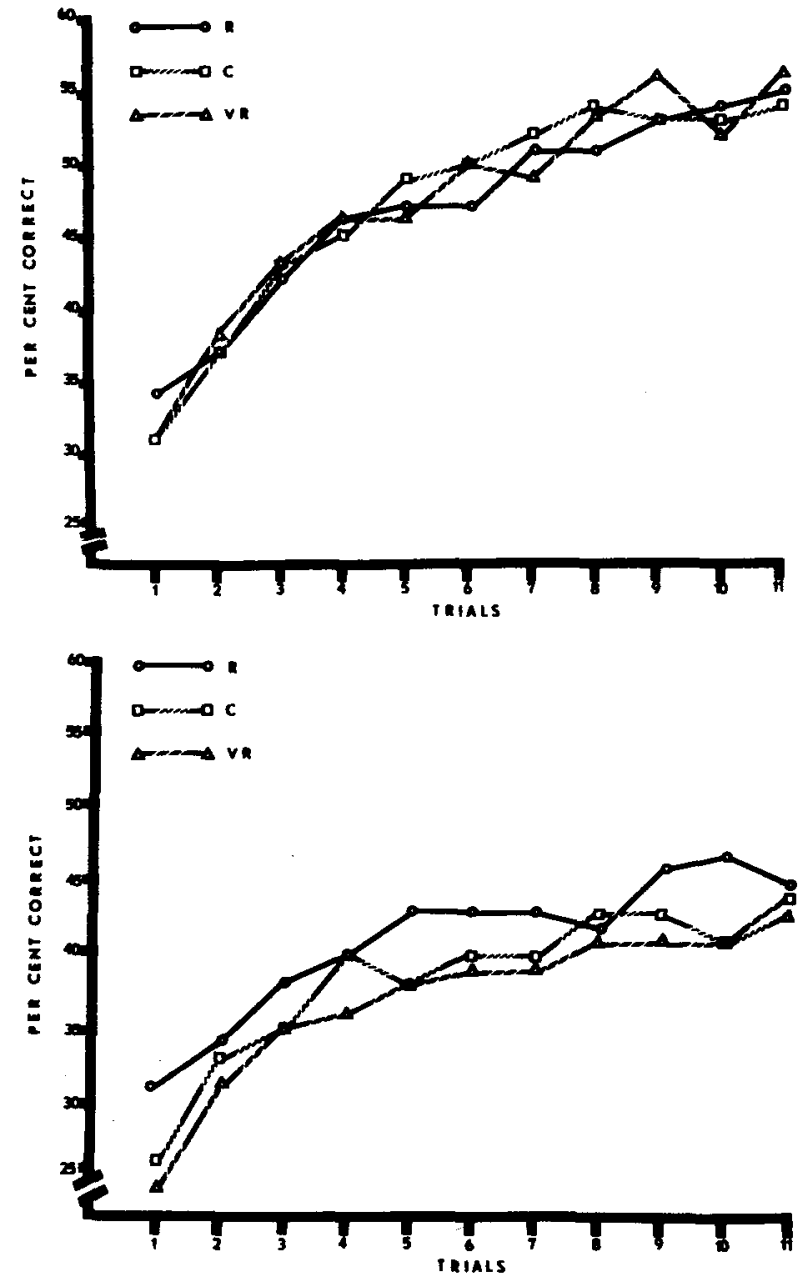

Figure 4. (Above) Percent of items recalled correctly by the normal group in the rehearsal (R), control (C)), and von Restorff (VR) conditions on each trial (Below) Percent of items recalled correctly by the retarded group in the rehearsal (R), control (C), and von Restorff (VR) conditions on each trial.

repetition aids primary but not secondary memory.

As for relative von Restorff effects, when incremented $\mathrm{dB}$ level is the isolating factor the results are consistent with previous studies in which normal groups were more susceptible to the visual phenomenon than retarded groups of approximately equivalent CA (Deutsch \& Sternlicht, 1967; McManis, 1966; Sternlicht \& Deutsch, 1966) and, when the list was of sufficient length, of equivalent MA. The normal group recalled the isolated item earlier, which suggests that order of learning strategy may partially account for group differences on the isolated item (Jensen, 1962).

That neither group demonstrated the VR effect on Trial 1 of that condition is of interest, since differences in retention or strategy by the groups did not affect initial performance. It can only be speculated that this phenomenon, as demonstrated here, requires a conscious level or awareness which would result in eventually better retention of an item by a higher-IQ group after 
the presentation of succeeding homogeneous items. The greater interference of nine succeeding control items in this study as compared with the four succeeding control items in the Winters and Attlee (1974) study would explain why the normal and retarded groups in the latter study did not differ in the performance on the isolated item but did in this study. Also, the strategy of recalling a heterogeneous item sooner than homogeneous items is congruent with previous findings (Winters \& Attlee, 1974) that normals are more consistent in their order of recall than retarded persons.

\section{REFERENCES}

Atkinson, R. C., \& Shiffrin, R. M. Human memory: A proposed system and its control processes. In $K$. W. Spence and J. T. Spence (Eds.), The psychology of learning and motivation (Vol. 2). New York: Academic Press, 1968.

Battig. W. F., Allen, M., \& Jensen, A. R. Priority of free recall of newly learned items. Journal of Verbal Learning and Verbal Behavior, 1965, 4, 175-179.

Belmont, J. M., \& Butterfield, E. C. The relations of short-term memory to development and intelligence. In L. P. Lipsitt and $\mathrm{H}$. W. Reese (Eds.), Advances in child development and behavior (Vol. 4). New York: Academic Press, 1969.

Belmont, J. M., \& Butterfield, E. C. Leaming strategies as determinants of memory deficiencies. Cognitive Psychology, $1971,2,411-420$.

Bray, $N$. $W$. Controlled forgetting in the retarded. Cognttive Psychology, 1973, 5, 288-309.

Brown, A. L. The role of strategic behavior in retardate memory. In $\mathbf{N} . \mathbf{R}$. Ellis (Ed.). International review of research in mental retardation (Vol. 7). New York: Academic Press, 1974.

Brown, A. L., Campione, J. C., \& Murphy, M. D. Keeping track of changing variables: Long term retention of a trained rehearsal strategy by retarded adolescents. American Journa of Mental Deficiency, 1974, 78, 446-453.

Brown, A. L., Campione, J. C., Bray, N. W., \& Wilcox, B. L. Keeping track of changing variables: Effects of rehearsa training and rehearsal prevention in normal and retarded adolescents. Joumal of Experimental Psychology, 1973, 101 123-131.

Brown, S. C., \& Thompson, C. P. Relationship between item strength and order of free recall. Journal of Verbal Learning and Verbal Behavior, 1971, 10, 444-448.

Butterfield, E. C.. Wambold, C., \& Belmont, J. M. On the theory and practice of improving short-term memory. American Joumal of Mental Deficiency, 1973, 77, 654-669.

Deutsch, M. R. \& Sternlicht, M. The role of "surprise" in the von Restorff effect. Joumal of General Psy chology, 1967, 96, 151-159.

Einstein, G. O., Pellegrino, J. W., Mondani, M. S., \& Battig, W. F. Free-recall performance as a function of overt rehearsal frequency. Joumal of Experimental Psychology, 1974, 103, 440-449.

Ellis, N. R. Memory processes in retardates and normals. In N. R. Elis (Ed.), International review of research in mental retardation (Vol, 4). New York: Academic Press, 1970.
Fischler, I., Rundus, D., \& Atkinson, R. C, Effects of overt rehearsal processes on free recall. Psych onomic Science, 1970 19, 249-250.

Glanzer, M., \& Meinzer, A. The effects of intralist activity on free recall. Journal of Verbal Learning and Verbal Behavior, $1966,6,928-935$.

Glidden, L. M. Meaningfulness, serial position and retention interval in recognition short-term memory. Journal of Experimental Child Psychology, 1972, 13, 154-164.

Greenfield, D., Zieger, W., Fisher, M. A., \& Zeaman, D. Effects on retroaction of the learned strength of interpolated material. Joumal of Experimental Child Psychology, 1974, 17, 242-249.

Herriot, P., \& Cox, A. M. Subjective organization and clustering in the free recall of intellectually-subnormal children. American Joumal of Mental Deficiency, 1971, 75, 702-711.

Jacoby, L. L. Encoding processes, rehearsal, and recall requirements. Journal of Verbal Learning and Verbal Behavior, 1973, 12, 302-310.

Jensen, A. R. An empirical theory of the serial-position effect. Journal of Psy chology, 1962, 53, 127-142.

Jensen, A. R. Rote learning in retarded adults and normal children. American Joumal of Mental Deficiency, 1965, 69, 828-834.

Kellas, G., Ashcraft, M. H., \& Johnson, N. S. Rehearsal processes in the short-term memory performance of mildly retarded adolescents. American Joumal of Mental Deficiency, 1973, 77, 670-679.

Kingsley, P. R., \& Hagen, J. W. Induced vs, spontaneous rehearsal in short-term memory in nursery school children. Developmental Psy chology, 1969, 1, 40-46.

Leicht, K. L., \& Johnson, R. P. Effects of rehearsal instructions on recall and organization in free learning of retardates. American Journal of Mental Deficiency, 1970, 75, 163-167.

McManis, $D$, L. The von Restorff effect in serial learning by normal and retarded subjects. American Journal of Mental Deficiency, $1966,70,569-575$.

Milgram, M. A. The effects of M.A. and I.Q. on verbal mediation in paired associate learning. Journal of Genetic Psychology, $1968,113,129-143$.

Nelson, $K$. J. The organization of free recall of young children. Joumal of Experimental Child Psy chology, 1969, 284-295.

Rundus, D. Analy sis of rehearsal processes in free recall. Journal of Experimental Psy chology, 1971, 89, 63-77.

Rundus, D., \& Atkinson, R. C. Rehearsal processes in free recall: A procedure for direct observation. Joumal of Verbal Learning and Verbal Behavior, 1970,9,99-105.

Spitz, H. H. The role of input organization in the learning and memory of mental retardates. In N. R. Ellis (Ed.), International review of research in mental retardation (Vol. 2). New York: Academic Press, 1966.

Sternlicht, M., Deutsch, M. R. Cognition in the mentally retarded: The von Restorff effect. Joumal of Mental Deficiency Research, 1966, 10, 63-68.

Winters, J. J., Jr., \& Attlee, L. C. The von Restorff effect and measures of organization in normals and retardates. Memory \& Cognition, 1974, 2, 301-305.

Winters, J. J., Jr., Gerjuoy, I. R., Crown, P., \& Gorrell, R. Eye movem ents and verbal reports in tachistoscopic recognition by normals and retardates. Child Development, 1967, 38, 1193-1199.

(Recevied for publication August 16, 1974: revision accepted October 14, 1974.) 